\title{
Wolf (Canis lupus) Predation Impacts on Livestock Production: Direct Effects, Indirect Effects, and Implications for Compensation Ratios
}

\author{
Jordan R. Steele, ${ }^{1}$ Benjamin S. Rashford, ${ }^{2}$ Thomas K. Foulke, ${ }^{3}$ John A. Tanaka, ${ }^{4}$ and David T. Taylor ${ }^{5}$ \\ Authors are ${ }^{1}$ Research Assistant, ${ }^{2}$ Associate Professor, ${ }^{3}$ Senior Research Scientist, and ${ }^{5}$ Professor, Agricultural and Applied Economics, University of \\ Wyoming, Laramie, WY 82071, USA; and ${ }^{4}$ Professor, Ecosystem Science and Management, University of Wyoming, Laramie, WY 82071, USA.
}

\begin{abstract}
Growing wolf (Canis lupus L.) populations in the US Rocky Mountain Region have increased conflicts between livestock production and wolf conservation. Given that the costs of large carnivore conservation are disproportionately borne by local livestock producers, the United States uses compensation for wolf damage to reduce conflicts and mediate negative attitudes toward the predators. Current compensation programs, however, only consider the direct effects of wolf predation. Indirect effects, such as wolf effects on weaning weights, and conception rates, may also reduce profitability. By not including indirect wolf effects, compensation programs may systematically undercompensate ranchers. We use a stochastic budget model of a representative cow-calf ranch in northwest Wyoming to estimate the economic impact of both direct (death loss and injured calves) and indirect effects (decreased weaning weights, decreased conception rates, and increased cattle sickness) of wolf predation. Our results suggest that short-run (i.e., year-to-year) financial impacts of wolf indirect effects may be as large as or larger than the direct effects. Including indirect effects implies that the compensation ratio (i.e., number of calves compensated per confirmed depredation) necessary to fully offset the financial impacts of wolves would need to be two to three times larger than current 7:1 compensation ratio used in Wyoming.
\end{abstract}

Key Words: cattle production, compensation, economics, predation, wildlife damage, wolves

\section{INTRODUCTION}

Controversy over the reintroduction of wolves (Canis lupus L.) remains a frequent newspaper headline across the US Rocky Mountain region. Much of the controversy stems from wolf depredation of livestock, which has steadily increased since reintroduction in 1995 (e.g., USFWS 2011). Given that the costs of large carnivore conservation are disproportionately borne by local livestock producers, the United Statesfollowing the example of other countries-uses compensation for wolf damage to reduce conflicts and mediate negative attitudes toward the predators (Schwerdtner and Gruber 2007, Dickman et al. 2011).

Though their ability to achieve conservation goals has been questioned (Boitani et al. 2010), designing effective compensation schemes requires a more thorough accounting of the costs large carnivores impose on livestock producers. Most compensation programs only attempt to offset the direct effect of livestock losses (e.g., animals predated). Wolves and other large carnivores can also have a variety of indirect effects (e.g., causing inefficient livestock weight gain) that are not captured in estimates of direct losses (Rashford et al. 2010). We use a stochastic budget model of a representative cow-calf operation in northwestern Wyoming to estimate the potential economic impact of both direct and indirect effects of wolf predation. Given the estimated economic impact, we then infer the compensation rates necessary to fully offset the direct and indirect effects of wolves.

Correspondance: Benjamin S. Rashford, Dept of Agricultural and Applied Economics, University of Wyoming, Laramie, WY 82071, USA. Email: brashfor@uwyo.edu

Manuscript received 8 February 2013; manuscript accepted 25 June 2013.

(c) 2013 The Society for Range Management
Programs that compensate for livestock predation are common where large predators have been reintroduced or are protected by public policy (Dickman et al. 2011). Though compensation mechanisms differ, most programs only compensate livestock owners for confirmed or verifiable losses. Confirming compensatory losses, however, can be difficult. Evidence of the predator at fault can disappear quickly or be contaminated by scavengers (Nyhus et al. 2005). Addressing unverified losses is one of the most critical problems for compensation programs since these losses further fuel negative attitudes toward predators and potentially toward conservation/ compensation programs. Many programs therefore use compensation ratios (or similar mechanisms) to address unverified losses. Compensation ratios explicitly recognize that for every verified predation event there are likely several unverified events. In the case of wolves in the northwestern United States, compensation programs currently compensate at a ratio of seven to one for cattle; for each cow or calf verified as being predated by wolves, the owner is compensated seven times the market value (USFWS 2011). This ratio is justified by studies of detection probability in the Rocky Mountain region (Oakleaf 2003), and thus is clearly intended to offset unverified losses.

Compensation ratios greater than one attempt to accurately compensate landowners for the full cost they bear in predator conservation. Even if compensation ratios are chosen carefully, however, programs that only compensate for the direct effect of predation may still undercompensate livestock owners. The value of cattle, for example, may not be accurately captured by market prices because of the timing of predation relative to the cattle price cycle, or because market rates do not reflect producer investments in genetics and acclimation (Ashcroft et al. 2010).

There is also mounting scientific evidence that large predators can have other more subtle effects on free-ranging cattle. Cattle 
exposed to large carnivores increase their vigilance behavior, may avoid certain areas (e.g., small pastures surrounded by dense cover), and are more prone to flight events (Kluever et al. 2008; Ashcroft et al. 2010; Sommers et al. 2010; Breck et al. 2012). The extent to which these behavioral changes affect financial returns is unclear. Some evidence suggests that cattle exposed to predators forage less efficiently and thus experience lower average daily weight gain (Ashcroft et al. 2010). Cattle herds exposed to predators can also have lower conception rates, either due to stress (Howery and DeLiberto 2004) or because cattle used as replacements do not breed as efficiently as those lost to predators (Ashcroft et al. 2010). There is also evidence that predation-related stress and injuries increase cattle vulnerability to sickness and disease (Howery and DeLiberto 2004; Lehmkuhler et al. 2007; Laporte et al. 2010), which can increase producer expenditures on medicine and veterinary services (Ashcroft et al. 2010). Producers in wolf country may also experience increased management costs due to checking animals or repairing fences more frequently, and due to management time expended to confirm depredations (Lehmkuhler et al. 2007; Sommers et al. 2010).

Although some studies have considered the economic impacts of wolf predation on cattle production, they have generally focused on the direct effects of predation (Muhly and Musiani 2009; Sommers et al. 2010; Hebblewhite 2011). The comprehensive economic impact, including direct and indirect effects, is largely absent in the literature, most likely because of the lack of scientific data required to quantify indirect effects. Rashford et al. (2010) attempted to estimate more comprehensive effects by including reductions in calf weaning weights and increases in management costs in a profit maximization model of a representative cow-calf ranch facing general predation. They found that reduction in weaning weights could have as large or larger of an effect on profitability as direct predation. Their model, however, only considered three effects of predation (i.e., death loss, reductions in weaning weights, and increased management costs), used largely hypothetical guesses at the size of the effects (e.g., straight percentage reductions in weaning weights), and only considered each effect in isolation, not cumulatively.

We simulated the potential economic impact on cow-calf production of a broad suite of direct and indirect effects of operating in areas inhabited by wolves. Since there is insufficient scientific research to precisely quantify all of the direct and indirect effects, we use available literature and anecdotal reports to quantify a suite of wolf effects in a stochastic budget model. The stochastic budget model allows us to simulate the economic impact of alternative levels of direct and indirect effects, both in isolation and cumulatively.

\section{METHODS}

\section{Representative Ranch Enterprise Budget}

We use an enterprise budget of a representative 400 head cowcalf ranch to simulate how wolves may affect ranch profitability. The budget model is specified using assumptions (e.g., bullto-cow ratios, conception, cull and natural death rates, and sale weights) consistent with cow-calf production in northwest Wyoming (see Steele 2012 for a detailed budget description).
Within the budget model, we divide the fiscal year into five seasons according to natural breaks in the cattle production process: winter feeding, calving, breeding, late summer grazing, and weaning. During each season, the budget model tracks activities (e.g., checking cattle) and their associated costs and revenues. The model operates on an annual basis, and thus represents a short-run model. We therefore do not consider fixed costs (e.g., interest on debt) and other long-run decisionmaking factors, which allows us to focus on the potential yearto-year impacts of wolves without considering the possibility of significant changes in ranch management (e.g., switching from a cow-calf to a stocker operation to reduce predation impacts). Since it is a short-run model, our primary measure of economic effects is the representative ranch's annual gross margin (i.e., revenue minus variable cost).

\section{Specifying Wolf Effects}

We model five potential effects of wolves on the representative ranch, including two direct effects: death loss (i.e., confirmed predated and missing cattle) and injured calves; and three indirect effects: decreased weaning weights, decreased conception rates, and increased cattle sickness. Though not inclusive of all the ways in which wolves can affect cattle production, these effects capture a range of possible direct and indirect effects and there exist data or reasonable assumptions to quantify them. Each effect is captured in the budget model through changes in specific production parameters or activities (Table 1). Death loss and injured calves are modeled by changing the death rate and veterinary expenditures, respectively. For death rates, we model natural deaths (e.g., during calving) separate from predation to isolate the wolf effect. The budget model also includes compensation for confirmed predations-we assume, following the literature and current policy, that one out of seven depredated animals is confirmed. Thus, by construction, our baseline model is designed to fully compensate for death loss.

We similarly adjust model parameters to incorporate indirect effects in the budget model. Decreases in weaning weights are modeled by changing the weights of heifer and steer calves at the end of the grazing season. We model decreased conception rates by adjusting the number of bred cows (i.e., at pregnancy testing in November). To maintain the annual characteristics of the model, we assume that all unbred cows are culled and replaced; thus, lower conception rates implies revenue from cull cow sales and costs associated with purchased replacements. Lastly, we model increased sickness by adjusting the number of calves that require medical treatment. Contrary to injured calves, we assume that stress-related increases in sickness can be treated by ranch employees (e.g., administering penicillin); thus, costs associated with medicine increase but there is no additional veterinary expenses.

There is relatively little scientific literature available to quantify many of our modeled wolf effects (i.e., determining the size of changes in model parameters). We therefore use a variety of sources to specify potential ranges in model parameters to capture each wolf effect. We use US Department of Agriculture data to parameterize nonwolf death loss (USDANASS 2011). We derive ranges for wolf predation rates from the published data in Sommers et al. (2010) and unpublished producer-collected data from Alberta, Canada (C. Sears, 
Table 1. Direction of change for model parameters used to simulate wolf effects in the cow-calf enterprise budget representative of production in northwestern Wyoming (June 2012).

\begin{tabular}{lccccc}
\hline & \multicolumn{5}{c}{ Wolf effect } \\
\cline { 2 - 6 } Budget parameter & $\begin{array}{c}\text { Death } \\
\text { loss }\end{array}$ & $\begin{array}{c}\text { Injured } \\
\text { calves }\end{array}$ & $\begin{array}{c}\text { Weaning } \\
\text { weight }\end{array}$ & $\begin{array}{c}\text { Conception } \\
\text { rate }\end{array}$ & Sickness \\
\hline Marketable calves & - & & & \\
Calf weights & & & - & \\
Owner labor hours & + & + & & \\
Truck use & + & + & & \\
Truck/haul expenses & - & & & \\
Veterinary expenses & & + & & + & \\
Cull cows & & & & \\
Replacement cows & & & & + \\
Medicine expense & & & & + \\
Brand inspections & - & & & + \\
\hline
\end{tabular}

unpublished data, 2008). Lastly, we derive ranges for indirecteffect parameters through interviews with five producers in northwest Wyoming; one producer in Alberta, Canada; and two wildlife services officials. The ranges are defined as percentages of difference from a "baseline" with no wolf effects (Table 2). The low scenario corresponds to the lowest reported value of each effect, and severe corresponds to the highest reported value. Each scenario implies different values for critical budget parameters (Table 3), which in turn affect output and cost and thus ranch gross margin.

\section{Simulating Wolf Effects on Short-Run Ranch Profitability}

Given that the literature measuring wolf effects is lacking and that no study has comprehensibly measured multiple wolf effects simultaneously, we use a Monte Carlo-style simulation to estimate the impact of wolves on short-run profitability. Specifically, we use the software @Risk (Palisade 2005) to define triangular distributions for each wolf effect. For each effect, we set the minimum value of the triangular distribution at zero (i.e., baseline parameter levels), the most likely value consistent with the average reported in the literature, and the maximum value consistent with the highest value observed in the literature. With each wolf effect defined by a distribution, we can randomly draw an observation for each wolf effect and calculate ranch gross margin. It would be counterintuitive, however, to treat separate wolf effects as independent-i.e., it would be unlikely to observe high death loss and low sickness. We therefore assume the individual wolf effect distributions are $50 \%$ correlated.

Table 2. Percentages of change from baseline used to simulate wolf effects in the cow-calf budget model representative of production in northwestern Wyoming (June 2012).

\begin{tabular}{lccc}
\hline & \multicolumn{3}{c}{ Level of effects } \\
\cline { 2 - 4 } Wolf effect & Low & Moderate & Severe \\
\hline Death loss & $1.50 \%$ & $3.60 \%$ & $7.50 \%$ \\
Injured calves & $0.25 \%$ & $0.50 \%$ & $2.75 \%$ \\
Weaning weights & $2.00 \%$ & $3.80 \%$ & $10.0 \%$ \\
Conception rates & $1.00 \%$ & $3.00 \%$ & $6.00 \%$ \\
Disease/sickness & $0.25 \%$ & $0.50 \%$ & $2.75 \%$ \\
\hline
\end{tabular}

Table 3. Model parameters for representative cow-calf budget in northwestern Wyoming corresponding to different levels (baseline, low, moderate, and severe) of wolf effects (June 2012).

\begin{tabular}{lcccc}
\hline Budget parameter & Baseline & Low & Moderate & Severe \\
\hline Calves to market & 380 & 375 & 367 & 352 \\
Injured calves & 0 & 1 & 2 & 11 \\
Weaning weights & $\mathrm{S}^{1} 545$ & S 534 & S 524 & S 491 \\
& H 525 & H 515 & H 505 & H 473 \\
Cull cows & 60 & 64 & 72 & 84 \\
Treated calves & 2 & 3 & 4 & 13 \\
\hline${ }^{1}$ S indicates steers; H, heifers. & & & &
\end{tabular}

In addition to stochastic wolf effects, we also incorporate random output prices in our simulation. Cattle prices can vary substantially both within and across years, and previous research has noted the important role of prices in determining the magnitude of predation impacts (Ashcroft et al. 2010). We therefore use weekly prices from the Torrington, Wyoming, livestock auction from the period 1992-2011 to define cattle price distributions. All prices are adjusted to 2011 dollars using the producer price index (St Louis Federal Reserve 2011). We then use the distribution-fitting tool in @Risk to define distributions for all cattle prices in our representative ranch budget (i.e., prices for steer calves, heifer calves, cull cows, and cull bulls). Based on $\chi^{2}$, Kolmogorov-Smirnov, and AndersonDarling statistics, we use triangular distributions to model steer and heifer calf prices and log-logistic distributions to model cull cow and cull bull prices. We also use the historical price data to define correlations between all prices to assure that simulations draw realistic price sets.

Given the distributions described above, we randomly draw observations on wolf effects and prices to derive distributions over ranch gross margin for each wolf effect individually and all effects cumulatively. To assure that our results are not driven by extreme draws, we determine the number of draws necessary for the simulations to converge following Ross (2002). At 10000 iterations, average gross margin converges with a standard deviation approximately equal to the price of one calf, and additional draws do not significantly alter results. We therefore use 10000 iterations to derive gross margin distributions. To compare alternative scenarios, we use standard two-sided $t$ tests to test the statistical difference of estimated average gross margins, where variances are derived from the 10000 iterations.

Lastly, we use the simulation results to calculate compensation ratios that include both direct and indirect wolf effects. To be consistent with current policy, we define the compensation ratio in terms of confirmed predated calves. We calculate the compensation ratio for each iteration, and then average across the 10000 iterations to determine the expected fair compensation ratio. For each iteration the compensation ratio is calculated as

$$
\text { Compensation Ratio }=\frac{\left(\frac{\text { Gross Margin Difference from Baseline }}{\text { Confirmed Depredated Calves }}\right)}{\text { Average Price per Calf }}
$$

We determine the number of confirmed depredated calves by multiplying death loss (i.e., number of predated claves determined in each iteration) by the assumed detection rate of $14.3 \%$ (i.e., one out of seven predated calves are confirmed). The 
calculated compensation ratio is therefore the number of calves that must be compensated to equate the gross margin with wolf effects to the baseline gross margin with no wolf effects.

\section{RESULTS}

In the baseline scenario with no wolf effects, the representative ranch had an average gross margin of $\$ 47803$. Price variability, however, caused substantial variation, with a standard deviation in gross margin of approximately $\$ 40000$. The price variability implies that the representative ranch covers variable costs (i.e., has a positive gross margin) for most alternative price scenarios $(85.4 \%)$.

Each individual wolf effect decreases the representative ranch's gross margin and generally increases the variability in gross margin (Table 4). Increased disease/sickness, death loss (i.e., direct predation) with compensation, and injured calves have small negative impacts, with both decreasing average gross margin by $1 \%$ to $2 \%$ and causing no measurable change in variability. Wolf-induced reductions in conception rates and death loss without compensation decrease average gross margin by approximately $\$ 10000(20 \%)$ and cause the variability in gross margin to increase. Reductions in weaning weights have the largest effect, decreasing average gross margin by nearly $27 \%$ and increasing the variability in gross margin. The wolf effects that increase variability in gross margin (conception rates, death loss, and weaning weights) also increase the proportion of simulated years when the ranch's gross margin is negative. In each case, the percentage of years with negative gross margin increases from approximately $15 \%$ in the baseline to $20 \%$ with each wolf effect. In all of the individual effects cases, the difference in average gross margin is different than the baseline $(P<0.001)$.

Cumulatively, wolf effects shift the entire distribution of gross margin toward negative values and increase the relative variability in gross margin (Fig. 1). Thus, for the same set of randomly drawn prices, the distribution of gross margin with cumulative wolf effects has a maximum, minimum, and average value less than the baseline, and has more observations that generate negative gross margin. Average gross margin decreases by approximately $52 \%$ (from $\$ 47803$ to $\$ 23106$ ). Gross margin decreases across the full range of simulated prices, with a minimum decrease of $\$ 4738$ and maximum decrease of $\$ 51446$ when compared the baseline for the same

Table 4. Summary of individual wolf effects impact on gross margin for a representative cow-calf enterprise in northwest Wyoming, USA (June 2012).

\begin{tabular}{lccc}
\hline \multicolumn{1}{c}{ Wolf effects } & $\begin{array}{c}\text { Average gross } \\
\text { margin }\end{array}$ & $\begin{array}{c}\text { Coefficient } \\
\text { of variation }\end{array}$ & $\begin{array}{c}\text { \% Negative gross } \\
\text { margin }\end{array}$ \\
\hline Baseline & $\$ 47803.00$ & 0.85 & $14.6 \%$ \\
Disease/sickness & $\$ 47533.21$ & 0.85 & $14.8 \%$ \\
Death loss with compensation & $\$ 47352.60$ & 0.85 & $14.8 \%$ \\
Injured calves & $\$ 46942.01$ & 0.85 & $14.8 \%$ \\
Conception rates & $\$ 37535.83$ & 1.09 & $20.1 \%$ \\
Death loss without compensation & $\$ 37025.32$ & 1.05 & $19.4 \%$ \\
Weaning weights & $\$ 34948.81$ & 1.11 & $20.4 \%$ \\
\hline
\end{tabular}

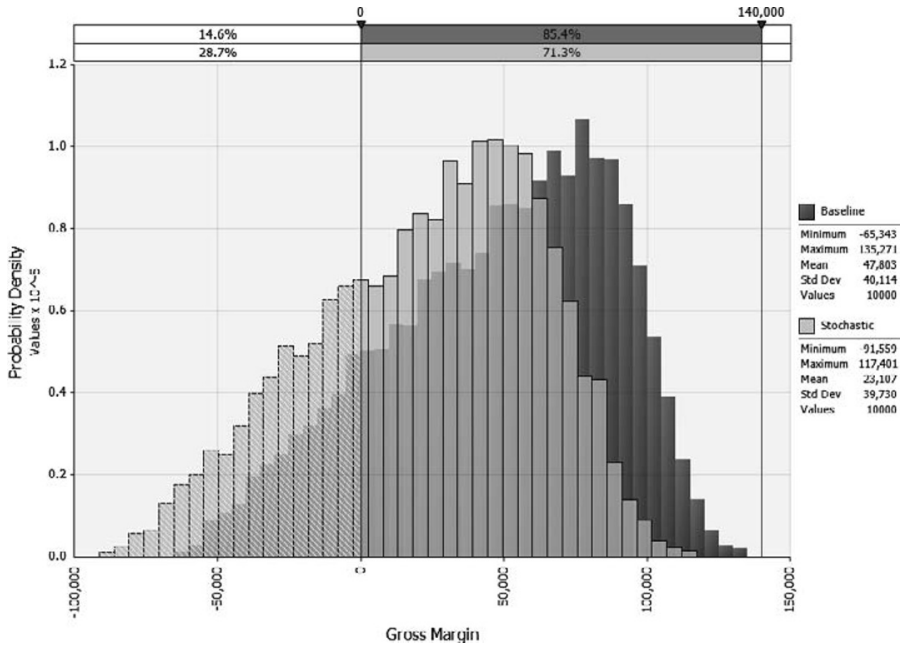

Figure 1. Comparison of gross margin distributions between the baseline scenario (i.e., no wolf effects) and cumulative stochastic wolf effects estimated using a representative cow-calf budget for northwestern Wyoming (June 2012).

set of prices. The variability in gross margin also increases substantially with a coefficient of variation of 1.72 compared to 0.85 in the baseline. Consequently, the proportion of negative years with cumulative stochastic wolf effects increases to $28.4 \%$ compared to $14.6 \%$ in the baseline.

The implied compensation ratios respond to wolf effects (Table 5). As designed, the budget model implies a compensation ratio equal to current policy (i.e., 7:1) when only death loss is considered. When all direct and indirect effects are cumulatively included, the implied compensation ratio increases threefold to $21: 1$. The implied compensation ratio with direct and indirect wolf effects ranges from 18:1 when wolf effects are fixed at the low level, to 24:1 when they are fixed at the most severe level observed in the region.

\section{DISCUSSION}

Our results suggest that the indirect effects of wolves on cowcalf production can be financially significant. Relative to a baseline with no wolf effects, the indirect effects of decreased conception rates and decreased weaning weights each have a negative effect on short-run profitability (average decrease of $\$ 10250$ to $\$ 12855$ ) that is comparable to, or larger than, direct predation (average decrease of $\$ 10778$ ). The indirect

Table 5. Comparison of compensation ratios across alternative wolf pressure scenarios derived using a stochastic budget model of cow-calf production in northwest Wyoming, USA (June 2012).

\begin{tabular}{lc}
\hline \multicolumn{1}{c}{ Wolf pressure scenario } & Compensation ratio \\
\hline Current policy & $7: 1$ \\
Only stochastic death loss & $7: 1$ \\
Cumulative stochastic effects & $21: 1$ \\
Low wolf effects & $18: 1$ \\
Moderate effects & $21: 1$ \\
Severe effects & $24: 1$ \\
\hline
\end{tabular}


effects of decreases in weaning weights and conception rates have large impacts because, like predation, they directly reduce the ranch's primary revenue source-calf production. The limited data available on weaning weight effects suggest predation pressure can decrease average calf weaning weights by $2 \%$ to $10 \%$ (i.e., $4-22 \mathrm{~kg}$ ), which at average prices $(\$ 0.55 \cdot \mathrm{kg})$ corresponds to substantial losses per affected calf. Our model, however, may tend to overestimate the weaning weight effects since it applies the same weight reduction (i.e., drawn randomly from the distribution in each simulation) to every calf in the herd. It is conceivable that calves would be affected differentially, but there is no literature or data available to model differential effects. Nevertheless, our bootstrapped approach should generate effects that are akin to a long-term average. Our results for weaning weight effects are also less severe than those estimated by Rashford et al. (2010), who found that a 5\% reduction in weaning weights could reduce average ranch profits by $40 \%$ (compared to our average estimate of a $27 \%$ reduction in gross margin).

In contrast, our model suggests that the indirect effects of increased disease/sickness and injuries have only small effects on short-run ranch profitability. These effects, and the expenditures associated with them, are often mentioned as potentially important indirect effects of large predators (Ashcroft et al. 2010). Although they do increase expenditures (e.g., costs of vaccines and veterinary care), from a financial perspective, these indirect effects have only minimal impacts on short-run profitability. Even in the worst-case scenarios included in our simulations (i.e., severe effects), disease/sickness reduced gross margin by only $\$ 688(1.4 \%)$ and injured calves decreased gross margin by $\$ 2210(4.6 \%)$. These results suggest that future efforts to quantify the indirect effects of large predators on livestock production should focus on how predator-induced stress affects weaning weights (e.g., forage efficiency and weight gain) and conception rates.

Our result that indirect effects can cause substantial financial losses has important implications for wolf compensation programs. The current compensation ratio of $7: 1$ may substantially underestimate the compensation necessary to fully offset the financial effects of wolves on livestock production. Our results indicate full compensation would require ratios ranging from $18: 1$ to $24: 1$ depending on the severity of indirect wolf effects. In 2012, wolves were confirmed to depredate 44 cattle in Wyoming (USFWS 2012). Using the average price from our data (\$729), the current 7:1 compensation ratio would imply total compensation costs of $\$ 224544$. Full compensation, however, would imply total compensation costs of $\$ 577399$ to $\$ 769865$.

Our estimated compensation ratios and total compensation costs depend on the limited data and assumptions we used to quantify indirect effects. To explore the importance of our assumptions, we also derived compensation ratios for a range of more conservative assumptions (Table 6). If we assume that there are no indirect effects on weaning weights and conception rates, then (as expected) the current compensation ratio is reasonably accurate since the remaining indirect effects have only small financial impacts. With no weaning weight effects (the largest and most difficult effect to quantify), the full compensation ratio is still nearly twice the current policy due to the effect of reduced conception rates. Alternatively, if we use
Table 6. Compensation ratios derived from a representative cow-calf budget in northwest Wyoming, USA using alternative assumptions about the magnitude of indirect wolf effects (June 2012).

\begin{tabular}{lc}
\hline \multicolumn{1}{c}{ Wolf pressure scenario } & Compensation ratio \\
\hline Baseline (i.e., current policy) & $7: 1$ \\
Zero weaning weights and conception rates & $8: 1$ \\
Zero weaning weights & $13: 1$ \\
Conservative weaning weights & $16: 1$ \\
Conservative weaning weights and conception rates & $13: 1$ \\
\hline
\end{tabular}

conservative estimates of the weaning weight and conception rate effects (i.e., define the indirect effect distribution over the range from zero to the average effect), the full compensation ratios range from 13:1 to 16:1. Thus, even with conservative assumptions, compensation ratios approximately twice as large as the current policy are necessary to fully offset both the direct and indirect effect of wolves on livestock production. As a result, total compensation costs would increase from \$224 544 using 7:1 compensation to approximately $\$ 417000$ to $\$ 513000$ using our conservative compensation ratios that account for direct and indirect effects.

Because we used a simulation approach, our results also highlight how variability in prices and wolf effects can impact livestock production. Livestock production is inherently risky, with profit margins continually fluctuating due to output price cycles and input cost changes. Random wolf effects add another source of risk (i.e., coefficient of variation increases); however, our results clearly indicate that output price variability is the most significant driver of risk. Though wolf effects increase the proportion of years with negative gross margin, the distribution of gross margin with and without wolf effects show similar variability. This implies that random prices, not random wolf effects, drive the variability in gross margin. High prices can even offset the most severe wolf effects (Table 7). Thus, years with severe wolf effects and high prices can be more profitable than years with no wolf effects and low prices. These results are consistent with landowner surveys in other regions that indicate nonpredation factors, such as market fluctuations and extreme weather, are greater threats to livestock production than wolves (Chavez et al. 2005).

Lastly, our short-run modeling approach may overestimate predation impacts because it does not account for potential changes in management. Alternative grazing practices, increased trapping or shooting efforts, and the use of guard dogs are common management practices to reduce the effects of predation (Woodroffe et al. 2005). Economic theory suggests that ranchers would adopt new management practices in the long run if the benefits outweighed the costs. Our short-run budget model approach, however, assumes that management practices and other long-run factors remain fixed. Thus, if alternative management practices could cost-effectively reduce the direct or indirect effects of wolves, our estimates of gross margin losses could be reduced. Any reduction in wolf effects would improve the long-run financial feasibility of our representative ranch. There is limited literature evidence, however, of the extent to which management practices can cost-effectively reduce the effects of wolves on cattle (Bjorge and Gunson 1986), and therefore our estimates likely represent 
Table 7. Comparison of gross margins between a scenario with no wolf effects (i.e., baseline) and low output prices, and a scenario with severe wolf effects and high output prices derived from a representative cow-calf budget for northwest Wyoming, USA (June 2012).

\begin{tabular}{lrrrr}
\hline & & \multicolumn{3}{c}{ Output prices $(\$ /$ cwt) } \\
\cline { 3 - 5 } & Gross margin & Steer & Heifer & \multicolumn{1}{c}{ Cow } \\
\hline Baseline & $-\$ 64,543.54$ & $\$ 92.41$ & $\$ 80.01$ & $\$ 45.09$ \\
Severe wolf effects & $\$ 71,051.71$ & $\$ 173.81$ & $\$ 164.28$ & $\$ 52.72$ \\
\hline
\end{tabular}

a conservative upper bound of the annual gross-margin impacts of wolves in both the short and long run.

\section{IMPLICATIONS}

Indirect predator effects have been identified for a variety of other predator and prey species (e.g., wolves have indirect effects on sheep, elk, and deer), and in other regions (e.g., from the US Southwest and Canada to Africa and India; Howery and Deliberto 2004; Muhly et al. 2010; Lehmkuhler et al. 2007; Ashcroft et al. 2010). Our finding in northwestern Wyoming that total financial impacts of wolves on cattle production can be much larger than just the direct predation losses therefore likely apply very broadly. Since compensation schemes are applied across the globe to encourage landowner support of, and participation in, carnivore conservation (Dickman et al. 2011), policy-makers need to consider the indirect effects of predators on local livestock production to design effective compensation schemes.

Current compensation schemes, which ignore the indirect effects of predators, may significantly undercompensate landowners for their role in predator conservation. In an era of high subsidies, full compensation for predator losses would still be small relative to other agricultural subsidies (e.g., total US corn subsidies in 2012 of $\$ 3$ billion is nearly 5000 times larger than the total amount spent on wolf-related compensation). Fully compensating, or even overcompensating using a fixed payment scheme, may be justified if it enlivens landowner participation (or reduces litigation) by making predators an asset rather than a liability. Such participation is critical to carnivore conservation, especially in the developing world. The tradeoff between full compensation and the moral hazard it could create (i.e., the disincentive to undertake private management actions to reduce predation), however, needs further research if compensation schemes are to be economically efficient.

\section{LITERATURE CITED}

Ashcroft, N. K., C. P. Mathis, S. T. Smallidge, J. M. Fowler, and T. T. Baker. 2010. Reestablishment of the Mexican gray wolf: the economics of depredation. Las Cruces, NM, USA: New Mexico State University, Range Improvement Task Force. Report 80. $16 \mathrm{p}$.

BJoRge, R. R., AND J. R. Gunson. 1986. Evaluation of wolf control to reduce cattle predation in Alberta Canada. Journal of Range Management 38(6):483-487.

Boitani, L., P. Ciuccl, and E. Raganella-Peliccionı. 2010. Ex-post compensation payments for wolf predation on livestock in Italy: a tool for conservation? Wildlife Research 37:722730.

Breck, S., P. Clark, L. Howery, D. Johnson, B. Kluever, S. Smallidge, and A. Cibils. 2012. A perspective on livestock-wolf interactions on western rangelands. Rangelands 34(5):6-11.
Chavez, A. S. S., E. M. Gese, and F. S. Kranich. 2005. Attitudes of rural landowners toward wolves in northwestern Minnesota. Wildlife Society Bulletin 33:517-527.

Dickman, A. J., E. A. Macdonald, and D. W. Macdonald. 2011. A review of financial instruments to pay for predator conservation and encourage human-carnivore coexistence. Proceedings of the National Academy of Sciences of the United States of America 108:13937-13944.

HEBBLEWHITE, M. 2011. Unreliable knowledge about economic impacts of large carnivores on bovine calves. The Journal of Wildlife Management 75:1724-1730.

Howery, L. D., AND T. J. DeLiberTo. 2004. Indirect effects of carnivores on livestock foraging behavior and production. Sheep \& Goat Research Journal 19:53-57.

Kluever, B. M., S. W. Breck, L. D. Howery, P. R. Krausman, and D. L. Bergman. 2008. Vigilance in cattle: the influence of predation, social interactions, and environmental factors. Rangeland Ecology \& Management 61:321-328.

Laporte, I., T. B. Muhly, J. A. Pitt, M. Alexander, and M. Musiani. 2010. Effects of wolves on elk and cattle behaviors: implications for livestock production and wolf conservation. PLoS One 5:1-9.

Lehmkuhler, J., G. Palmquist, D. Ruid, B. Willging, and A. Wrdeven. 2007. Effects of wolves and other predators on farms in Wisconsin: beyond verified losses. Madison, WI, USA: Wisconsin Department of Natural Resources, Wisconsin Wolf Science Committee. Pub-ER-658. $15 \mathrm{p}$.

Muhly, T. B., M. Alexander, M. S. Boyce, R. Creasey, M. Hebblewhite, D. Paton, J. A. Pitt, and M. Musianl. 2010. Differential risk effects of wolves on wild versus domestic prey have consequences for conservation. Oikos 119:1243-1254.

Muhly, T. B., AND M. Musian. 2009. Livestock depredation by wolves and the ranching economy in the northwestern U.S. Ecological Economics 68:2439-2450.

Nymus, P. J., S. A. Osofsky, P. Ferraro, H. Fischer, and F. Madden. 2005. Bearing the costs of human-wildlife conflict: the challenges of compensation schemes. In: R. Woodroffe, S. Thirgood, and A. Rabinowitz [EDS.]. People and wildlife: conflict or coexistence? Cambridge, UK: Cambridge University Press. p. 107-121.

OAKLEAF, J. 2003. Effects of wolves on livestock calf survival and movements in central Idaho. Journal of Wildlife Management 67:299-306.

Palisade [computer program]. 2005. @RISK. Ithaca, NY, USA: Palisade Corporation.

Rashford, B. S., T. Foulke, and D. T. Taylor. 2010. Ranch-level economic impacts of predation in a range livestock system. Rangelands 32(3):21-26.

Ross, S. M. 2002. Simulation. San Diego, CA, USA: Academic Press. 312 p.

SchWerdtner, K., AND B. Gruber. 2007. A conceptual framework for damage compensation schemes. Biological Conservation 134:354-360.

SteELE, J. R. 2012. Wolf reintroduction: direct and indirect effects for western Wyoming cattle producers [thesis]. Laramie, WY, USA: University of Wyoming. $73 \mathrm{p}$.

St LouIs Federal Reserve. 2011. Producer price index: all commodities. Available at: http:// research.stlouisfed.org/fred2/series/PPIACO?cid=31. Accessed 2 February 2012.

Sommers, A. P., C. C. Price, C. D. Urbigkit, and E. M. Peterson. 2010. Quantifying economic impacts of large-carnivore depredation on bovine calves. Journal of Wildlife Management 74:1425-1434.

[USDA-NASS] US Department of Agriculture-National Agricultural Statistics Service. 2011. Wyoming 2011 Agricultural Statistics. Cheyenne, WY, USA: Wyoming Field Office, USDA. $104 \mathrm{p}$.

[USFWS] US Fish and WildlfFe Service. 2011. Rocky Mountain wolf recovery 2011 interagency annual report, table $5 \mathrm{~b}$-Northern Rocky Mountain confirmed wolf depredations by state. Available at: http://www.fws.gov/mountain-prairie/species/ mammals/wolf/annualrpt11/index.html. Accessed 26 November 2012.

USFWS. 2012. Rocky Mountain wolf recovery 2012 interagency annual report. Available at: http://www.fws.gov/mountain-prairie/species/mammals/wolf/annualrpt12/. Accessed 20 May 2013.

Woodroffe, R., S. Thirgood, and A. Rabinowitz [eds.] 2005. People and wildlife, conflict or coexistence? Cambridge, UK: Cambridge University Press. 516 p. 